\title{
Characterization of Cu-30Mo Alloys Synthesized by Mechanical Alloying
}

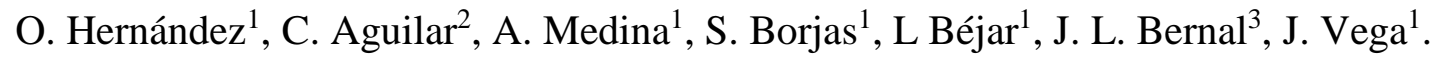 \\ 1. UMSNH. Ciudad Universitaria Morelia, Michoacán. 58000 \\ 2. Universidad Técnica Federico Santa Maria. Av. España 1680 Valparaiso Chile) \\ 3. TecNM. Instituto Tecnológico de Orizaba, Departamento de Ingeniería Mecánica Oriente 9. Emiliano \\ Zapata Sur Orizaba Veracrúz 94320.
}

There has been a growing interest in the synthesis of materials with nanoscale microstructures. Copper and its alloys have good electrical and thermal conductivity and good resistance to corrosion [1]. The final properties of copper and its alloys greatly depend on the amount of the alloying elements and even on small additions of impurities; hence the method of producing the copper alloys is very important and decisive for the final application.

The common synthesis techniques are: chemical vapor deposition, chemical precipitation, sol-gel processing, gas-phase condensation, physical evaporation, sputtering and mechanical alloying [2,3]. In conventional casting, alloy grain size is difficult to control. Coarse grains deteriorate the mechanical properties of the alloys. It has been reported that mechanical alloying (MA) and powder metallurgical techniques can be used to prepare alloys $\mathrm{Cu}$-based. MA can reduce oxidation because a new phase is formed, and produces a pre-alloyed powder that shortens the sintering time.

In this work we report on the structural and chemical characterization of $\mathrm{Cu}-30 \mathrm{Mo}$ alloy synthesized by mechanical alloying, with milling time of $10 \mathrm{~h}$. Scanning electron microscopy (SEM) and energy dispersive spectroscopy (EDS) were used to identify the morphology formed after the mechanical alloying process and chemical compositon of the particles formed respectively.

Figure 1a shows particles milled for 10 hours. The particles are rounded and the average size is between 5-25 $\mu \mathrm{m}$. Agglomeration of the particles can also be seen in the same figure, indicating welding during the milling stage. The average size of the particles depends on the extent of welding and fragmentation. The chemical composition of the particles is observed in the Figure 1b where we can observe the Copper and Molybdenum peaks, we can also appreciate contamination of the Iron which comes from the steel balls used during the milling. Results of the quantification of the elements showed that the particles are composed of $76.04 \%$ wt, $23.57 \%$ wt and $0.39 \%$ wt of $\mathrm{Cu}$, Mo and Fe respectively. Figure $2 \mathrm{a}$ and $2 \mathrm{~b}$ shows the mapping of the particles shown in figure 1a, indicating that the milling time used formed particles of copper with embedded molybdenum.

\section{References}

[1] O. Alvarez-Fregoso, S. López, J. A. Juárez-Islas, M. García, E. Martínez, M. A. Alvarez-Pérez, J.

Ch. Ramírez, S. Granados. Phys. Stat. Sol. B. Volume 220, (2000), p. 575

[2] R. Mendoza, J. Huante, V. Camacho, O. Alvarez-Fregoso, and J. A. Juarez-Islas, J. Mater. Engng. and Perf. Volume 8, (1999), p. 1

[3] Maria do Carmo, Amorim da Silva, Severino Jackson Guedes de Lima, Mat. Res. Volume 8. (2005), p. 169 

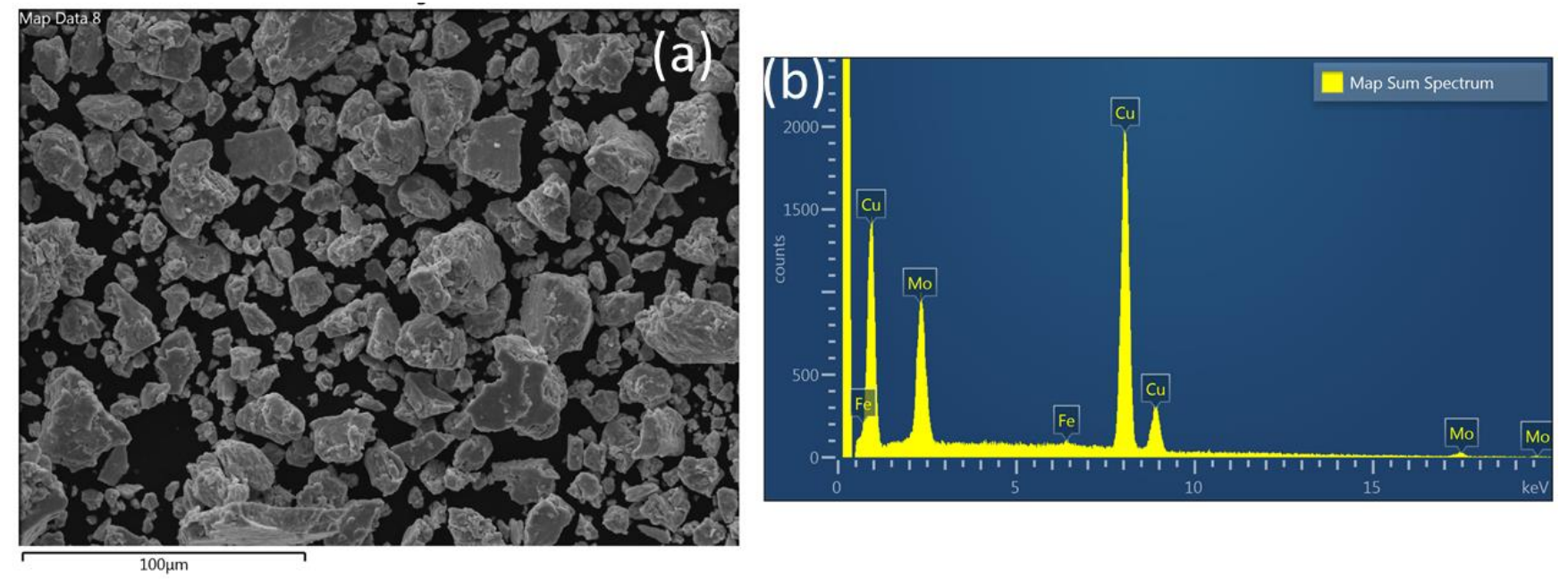

Figure 1. (a) SEM image of Cu-30Mo milled for $10 \mathrm{~h}$, (b) EDS analysis Co-30Mo milled for $10 \mathrm{~h}$
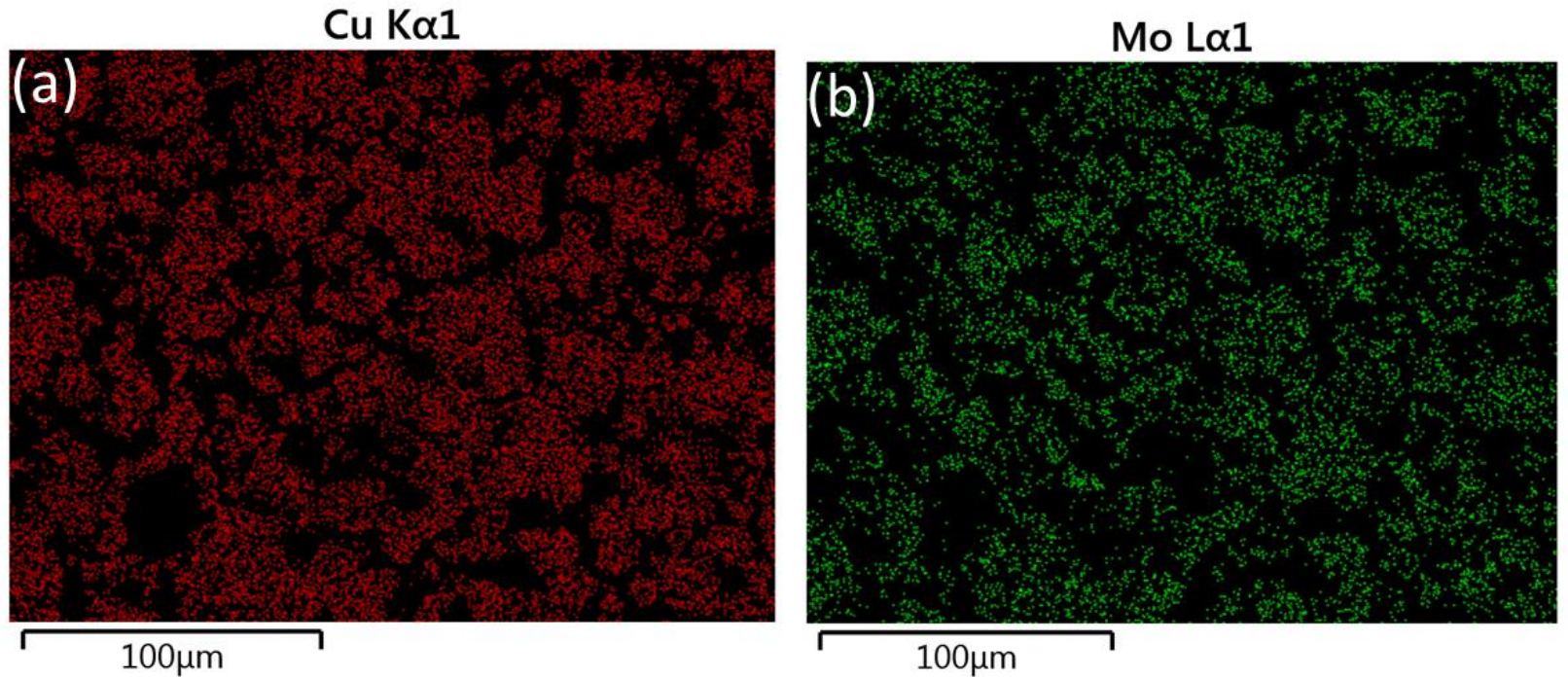

Figure 2. (a) and (b) Mapping analysis of the $\mathrm{Cu}$ and Mo respectively of $\mathrm{Cu}-30 \mathrm{Mo}$ milled for $10 \mathrm{~h}$ 